\title{
Editorial
}

\section{Extracurricular Activities and Student's Academic Performance}

\author{
Ahmad $\mathrm{M}^{1}$, Rahman $\mathrm{MF}^{2}$
}

Students participate in games, sports, cultural and educational club activities during their leisure time within college premises and these are referred to as extracurricular activities. It has been found that students who participate in extracurricular activities generally benefit from having better grades, higher standardized test scores and educational attainment. They attend classes more regularly hence decrease in absenteeism, have a higher self concept and an increased connectedness to the academic institution. Participants in out-of-class activities often learn skills like teamwork and leadership, positive youth development while stay away from likelihood of illicit drug use and related problems of personal behaviors.

Eccles, in his study found that participation in extracurricular activities is related to indicators of healthy development. He described five different types of extracurricular activities that students took part in which are: pro-social activities, team sports, performing arts, school-involvement activities, and academic clubs ${ }^{1}$. Morrissey describes positive youth development as encompassing five constructs: Competence in academic, social and vocational areas; Confidence; Connection to family, community and peers; Character and caring and Compassion ${ }^{2}$. These are also known as the Five Cs of positive attributes for youth. By engaging in extracurricular activities, students are motivated to increase their capability and do their best. Competing in an extempore speech contest may help a student to gain confidence. Scouting organization, blood donation programme, tree planting, cleanliness drive, free outdoor medical camps may help the student develop character and connect with the community. Social service or volunteering might help a student to project a caring and compassion attitude toward others. It is important to understand exactly how each activity is impacting a student and what type of positive development is taking place ${ }^{3}$.
According to Olson, participation in a music competition lessened students' feelings of alienation, promoted individual growth and provide a social network and a support system bond between home and academic institute ${ }^{4 .}$ Another example of a helpful extracurricular activity is participation in athletics. Which teach them to interact with peers, work for the best interest of the team and learn to follow instructions of the team leader. This type of interaction may contribute to the student athlete's development of self-identity ${ }^{4,5}$. A student's identification and involvement with sports creates a social network for these student athletes that emphasizes the value of the academics. Participation in sports may also provide students with unique development opportunities that positively impact the student's social self-concept which may lead to a higher academic expectations and therefore better academic outcomes for student athletes. Adolescent students who do not have opportunities to identify with a particular group or who are affiliated with delinquent social groups are more likely to suffer negative repercussions including: dropout, suicide, substance abuse, or discipline problems ${ }^{6}$.

Darling, Caldwell and Smith suggested that participation in athletics is related to the following positive academic related outcomes including higher grade point average, fewer disciplinary referrals, lower absentee rates, decrease in dropout rates, stronger commitment to remain in the academic tract in coursework $^{4}$, Gilman stated that getting an adolescent involved in any activity may not gain success if following factors are not considered: (a) the perceived social status of the activity, (b) intrinsic interest in the activity, (c) the quality of the adolescent's social network, and (d) the non-parent adult who is part of the activity. It is important to consider that as school personnel, counselors should encourage the students to explore their options for activities to find the best fit ${ }^{7}$.

1. Lt Col Mushtaq Ahmad, MBBS, DFM, MCPS, FRSPH, Associate Professor \& Head, Dept of Forensic Medicine, AFMC, Dhaka 2. Major General Md Fashiur Rahman, $n d c$, MBBS, MPH, LLB, FCGP, MBA, MSS, Commandant, AFMC, Dhaka. 
Barden researched whether participation in athletics and co-curricular activities in high school provided significant educational benefits in the areas of discipline records, GPA, attendance records and dropout rate. Data were collected for the 2000-2001 school year from a school district located in eastern Georgia with four high schools. Six hundred participants represented proportional stratified sample and results showed that students participants had significantly higher GPA attendance and better discipline records than nonparticipants ${ }^{8}$. Strangely, time management is an important issue for a student. Students who are customized in adding more commitments to their routine study, enjoy the effect of better time management. Extracurricular activitiy is a sort of recharging their brain after having arduous study work that get back the student to daily rountine study with fresh mood.

Armed Forces Medical College is a unique institution where students get the best possible opportunities to participate in extracurricular activities outside the class hour. These activities help them to nourish their intelligence, flourish their capabilities and cherish their minds. They participated in different national level competitions and already achieved some trophies of champion and runner up which are considered as feathers to decorate their caps. The original paper in this issue on-"Effect of Extra Curricular Activity on Student's Academic Performance" is a time worthy approach by the researchers which will enrich our knowledge and encourage others to perform more studies on this topic in future based on our country perspective. All educational institutes should provide at least some facilities of extracurricular activities to students which will guide them to the highway of a better and prosperous future.

\section{References}

1. Eccles J. Extracurricular activities and adolescent development. Journal of Social Issues 2003; 59(4): 865-89.

2. Roth P, Bobko P. College grade point average as a personnel selection device: Ethnic group differences and potential adverse impact.Journal of Applied Psychology 2000; 85(3):399-406.

3. Morrissey K. The relationship between out-of-school activities and positive youth development: An investigation of the influences of communities and family. Adolescence 2005; 40:67-85.

4. Darling N, Caldwell L, Smith R. Participation in school-based extracurricular activities and adolescent adjustment. Journal of Leisure Research 2005; 37(1): 51-76.

5. Marsh HW \& Kleitman S. Extracurricular school activities: The good, the bad, and the non-linear. Harvard Educational Review 2002; 72:464-514.

6. Smith SL. Athletics \& Academics. 1st ed. Research Starters. New York. 2008:58-78.

7. Gilman R. Structured extracurricular activities among adolescent findings and implications for school psychologists. Psychology in the Schools 2004;41(1): 4-9. The case for high school activities. National Federation of State High School Association. [Cited 2016 May 17] <Retrieved from: www.nfhs.org/case.htm>

8. Broh B. Linking extracurricular programming to academic achievement: Who benefits and why? Sociology of Education 2002; 75(1),69-95. 